\title{
Erzincan İlindeki Hayvansal Atıkların Biyogaz Potansiyelinin Araştırılması
}

\author{
*1Aslıhan Kurnuç Seyhan, ${ }^{2}$ Anıl Badem \\ 1*Erzincan Üniversitesi, Mühendislik Fakültesi, Makine Mühendisliği Bölümü, Erzincan, Türkiye, \\ akurnuc@erzincan.edu.tr \\ ${ }^{2}$ Erzincan Üniversitesi, Fen Bilimleri Enstitüsü, Makine Mühendisliği Anabilim Dalı, Erzincan, Türkiye \\ Geliş Tarihi: 2017-08-11 Kabul Tarihi: 2018-01-30
}

\section{$\ddot{O} \mathbf{z}$}

Fosil kökenli enerji kaynaklarının tükenebilir olması, çevreye olan olumsuz etkileri ve enerji ihtiyacının gün geçtikçe artması mevcut kaynakların daha etkin kullanımı yerli ve yenilenebilir enerji kaynaklarına yönelimi gerekli kılmıştır.

Temel geçim kaynağı tarım ve hayvancılık olan Erzincan ili yüzölçümünün \%37'si çayır ve meralardan oluşmaktadır. Bu durum, yem bitkisi çeşitlerinin geniş alanlarda yetiştirilmesine ve beraberinde hayvansal üretiminde gelişmesine neden olmuştur. Büyükbaş, küçükbaş ve kanatlı hayvan yetiştiriciliği yapılan Erzincan ilinde yılda 434469 ton hayvansal atık elde edilmektedir. Bu atıkların sürdürülebilir ve etkin bir biçimde kullanımının en iyi yollarından biri de biyogaz üretimidir.

Bu çalışmada, Erzincan Damızlık Sığır Yetiştiricileri Birliği ile Gıda, Tarım ve Hayvancılık il Müdürlüğü verileri kullanılarak, Erzincan ili hayvansal atıklardan elde edilebilir yıllık biyogaz miktarı $15511011 \mathrm{~m} 3$, elektrik enerjisi 38025864 kWhe ve 1sı enerjisi 35818027112 kcal olarak hesaplanmıștır. Erzincan'ın biyogaz kaynaklı elektrik kurulu gücü bakımından 4.3 MW'lık bir potansiyel barındırdığı, biyogaz ve enerji üretimi değerleri açısından da kayda değer bir nitelik taşıdığı görülmektedir.

Anahtar kelimeler: Biyogaz, Biyogaz Potansiyeli, Erzincan, Hayvansal Atık, Yenilenebilir Enerji

\section{Investigation of Biogas Potential of Animal Wastes in Erzincan Province}

\author{
${ }^{* 1}$ Erzincan University, Faculty of Engineering, Department of Mechanical Engineering, Erzincan, Turkey, \\ akurnuc@erzincan.edu.tr \\ ${ }^{2}$ Department University, Institute of Science and Technology, Department of Mechanical Engineering, Erzincan, \\ Turkey \\ Geliş Tarihi: 2017-08-11 Kabul Tarihi: 2018-01-30
}

\begin{abstract}
The fossil-based energy resource's is non-renewable and causing negative effects on the environment. Because of the ever-increasing need for energy, the more efficients use of existing resources and is necessary move towards domestic and renewable energy sources.

The main livelihood of agriculture and animal husbandry is $37 \%$ of Erzincan province's surface area is composed of meadow and grassland. This has led to the cultivation of feed plant varieties in large areas and the development of animal production. In Erzincan province where cattle, sheep and poultry are grown, 434469 tons of animal waste is obtained annually. Biogas production is one of the best ways to use these wastes in a sustainable and efficient way.

In this study, the amount of biogas available per year from Erzincan province animal wastes was calculated as $15511011 \mathrm{~m} 3$, electric energy $38025864 \mathrm{kWhe}$ and heat energy $35818027112 \mathrm{kcal}$ using data from Erzincan Cattle Breeders Association and Food, Agriculture and Livestock Provincial Directorate. It is observed that Erzincan has a potential of 4.3 MW in terms of biogas-derived electricity generation power and has an important capacity for biogas and energy production values.
\end{abstract}

Keywords: Biogas, Biogas Potential, Erzincan, Animal Waste, Renewable Energy

*Sorumlu Yazar: Erzincan Üniversitesi, Mühendislik Fakültesi, Makine Mühendisliği Bölümü, Erzincan, Türkiye, akurnuc@erzincan.edu.tr 


\section{GİRİş}

Dünya nüfusunun hızla artması ve gelişen sanayileşmeyle birlikte, enerji kaynakları kullanımı önemli seviyelere ulaşmıştır. Fosil yakıtlar dünyanın enerji arzında büyük paya sahiptir ve mevcut çevresel sorunlara, özellikle hava kirliliği ve küresel ısınmaya neden olur. Buna göre, kaynakların hızlı tükenmesi ve fiyat dalgalanmaları, dünya genelinde yenilenebilir enerji kaynakları eğiliminde bir artışa neden olmuştur [1].

Zamanla, hem doğal kaynakların eldesi ve temin edilebilirliği azalmaya başlamış, hem de doğal ortama verilen zararlar ile birlikte çevre kirliliğinde artış meydana gelmiştir. Son yıllarda enerji kaynak çeşitleri ve bunların çevresel etkileri çok tartışılan konulardan biri haline gelmiştir. Enerji kullanımının neden olduğu olumsuz çevresel etkilerin en düşük düzeylerde tutulabilmesi, sosyal ve ekonomik kalkınma açısından; temiz enerji talebinin, ucuz, güvenilir ve sürdürülebilir fiyattan karşılanması zorunludur.

$\mathrm{Bu}$ sebeple $\% 100$ yenilenebilir ve sürdürülebilir enerji kullanımı için çeşitli çalışmalar yapılmıştır [2]. Bu çalışmalardan birisi 2050 yılına kadar Avrupa Birliği (AB)'nde \%100 yenilenebilir enerji sistemi için bir senaryo sunarak, senaryonun teknik olarak mümkün olduğunu ve toplumun, uygun teknoloji, politik güç ve uygulama kabiliyeti ile gerçekleştirebileceği sonucuna varmaktadir [3].

Yenilenebilir enerji kaynakları içerisinde önemli bir yere sahip olan biyokütle, sürdürülebilir kalkınma modelleri içerisinde çevre ve enerji fonksiyonları açısından önemlidir. Biyokütle sadece sürdürülebilir kalkınmaya katkıda bulunmakla kalmıyor, aynı zamanda dünya nüfusunun tamamına enerji güvenliği sağlıyor ve sera gazı emisyonlarını azaltıyor. Bulunabilirliği ve iyi bilinen dönüştürme teknolojilerinin dışında biyokütle, en yakın talebi karşılamak ve enerji arz güvenliğini sağlamak için yakın gelecekte önemli enerji kaynaklarından biri olacaktır [4].

Biyokütle enerjisi; doğal orman, ormancılık ve orman endüstrisinden odun atıkları, evsel ve endüstriyel atıklar veya hayvan atıkları gibi bitki ve hayvan materyallerinden türetilmektedir [5-8].

Biyokütleden; filtrasyon, ekstraksiyon, boyut küçültmekırma ve öğütme, kurutma ve biriketleme yöntemlerini içeren fiziksel süreçler ile ya da termokimyasal ve biyokimyasal süreçlerini içeren dönüşüm süreçleri ile yakıt elde edilmektedir. Uygulamada başarısını kanıtlamış biyoyakıtların, dönüşüm süreçleri ve ürünleri Tablo 1.'de sunulmuştur.

Tablo 1. Biyoyakıtların dönüşüm süreçleri ve ürünleri

\begin{tabular}{|l|l|}
\hline \multicolumn{1}{|c|}{ Dönüşüm Süreci } & \multicolumn{1}{c|}{ Ürün } \\
\hline Biyometanlaştırma süreçleri & Biyogaz \\
\hline Biyofotoliz süreçleri & Hidrojen \\
\hline Fermentasyon süreçleri & Biyoetanol \\
\hline Piroliz süreçleri & Pirolitik sıvı \\
\hline Gazlaştırma süreçleri & Gaz yakıt \\
\hline Karbonizasyon süreçleri & Biyokömür \\
\hline Esterleşme süreçleri & Biyomotorin (Biyodizel) \\
\hline
\end{tabular}

$\mathrm{Bu}$ yakıtlar içinde biyogaz, biyoetanol ve biyomotorin önde yer almaktadır. Biyogaz organik maddelerin anaerobik (oksijensiz) ortamda, farklı mikroorganizma gruplarının varlığında, biyometanlaştırma süreçleri (havasiz bozunma-biyolojik bozunma-mikrobiyal bozunma-anaerobik fermentasyonun kontrollü süreci) ile elde edilen bir gaz karışımıdır [9].

Anaerobik biyolojik prosesten çıkan bu gaz karışımına, tekrarlanabilir temiz gaz olan ve kırsal enerji talebi sağlayabilen biyogaz denir [10]. Renksiz ve yanıcı bir gaz karışımı olan biyogazın, bileşiminde \%60-70 metan $\left(\mathrm{CH}_{4}\right)$, \%30-40 karbon dioksit $\left(\mathrm{CO}_{2}\right)$ ve az miktarda hidrojen sülfür $\left(\mathrm{H}_{2} \mathrm{~S}\right)$, hidrojen $\left(\mathrm{H}_{2}\right)$, karbon monoksit (CO) ve Nitrojen $\left(\mathrm{N}_{2}\right)$ bulunmaktadir [11-13]. Biyogaz doğal gaza alternatif bir gaz yakıt olarak doğrudan yakma-1sınma ve 1sitmada, motor yakıtı olarak, türbin yakıtı olarak, elektrik enerjisi elde edilmesinde, yakıt pili yakıtı olarak, doğal gaz içine katkı olarak ve kimyasalların üretiminde kullanılmaktadır [9].
Ülkemizde hayvan potansiyelinin, tarımsal alanların, hayvancılık ve tarımla uğraşan nüfusun fazla olmasından dolayı biyogaz; Türkiye için etkili bir enerji kaynağı potansiyelini taşımaktadır [14]. Türkiye'nin yıllık ve toplam geri kazanılabilir biyokütle enerji potansiyeli sirasiyla 32.6 ve 17.2 MTEP (Milyon Ton Eşdeğer Petrol) olarak tahmin edilmektedir. Bu enerji potansiyeli içerisinde hayvancılıktan yaklaşık 72 milyon ton y1llık hayvan gübresi tahmini yapılmaktadır [15]. Hayvan gübresinin büyük bir bölümünün doğrudan kırsal alanlarda 1sıtma amaciyla kontrolsüz depolanması ya da yakılmas1, gübrenin kalitesinde azalmaya, enerjinin çoğunun kaybına, koku ve görsel sorunlara, toprak ve su kirliliği gibi çeşitli çevre ve sağlık sorunlarına da sebep olmaktadır [16].

Hayvan atıklarından biyogaz üretimi, atıkların çevreye olan olumsuz etkilerinin azaltılmasının yanı sıra enerji üretiminde de kaynak olarak kullanılabilmesi ve proses sonucu yan ürün olan fermente gübrenin tarımda 
kullanılarak tarımsal verimliliğin artışına katkıda bulunabilmesi açısından önem arz etmektedir [17].

$\mathrm{Bu}$ çalışmada Erzincan İli ve ilçelerindeki hayvansal atık kaynaklı biyogaz potansiyelinin belirlenmesi amaçlanmıștır. Bu potansiyelin belirlenmesinde hayvan sayıları ile ilgili veriler saha çalışmalarından, birliklerden, kamu kurumları ve yerel enstitülerden alınmıştır. Çalışmanın özgünlüğü kayıtlı net veriler üzerinden çalıșılmış olmasıdır. Erzincan Damızlık Sığır Yetiştiricileri Birliği, Erzincan Gıda, Tarım ve Hayvancılık İl Müdürlüğü verileri kullanılarak Erzincan Merkez ve 8 ilçesinde Büyükbaş, Küçükbaş ve Kanatlı hayvan sayıları, türleri ve bu hayvanlardan elde edilebilecek atık miktarları belirlenerek, Erzincan ilinin hayvansal atı kaynaklı enerji potansiyeli hesaplanmıştır.

\subsection{Bölgedeki Hayvan Sayılarının Belirlenmesi}

Erzincan yöresinde hayvancılık, büyükbaş, küçükbaş ve kanatlı hayvancılık (kümes) sektörlerinde gelişmiştir. Büyükbaş olarak, inek, düve, boğa, tosun, erkek/dişi dana ve erkek/dişi buzağı yetiştiriciliği, küçükbaş olarak, koyun ve keçi yetiştiriciliği, kanatlı hayvanlar olarak da ördek, hindi, kaz ve yumurta/broiler tavuk yetiştiriciliği yapılmaktadır.

İlçe bazında küçükbaş ve kanatlı hayvan sayıları için Gıda, Tarım ve Hayvancılık İl Müdürlüğü verileri, büyükbaş hayvan sayıları için ise Erzincan Damızlık Sığır Yetiştiricileri Birliği verileri kullanılarak elde edilen en güncel veriler ile hayvan sayıları Tablo 2 'de görülmektedir.

Erzincan ilinde toplam büyükbaș hayvan sayısının 64867 olduğu ve bunun en büyük kısmını, 24646

\section{MATERYAL VE YÖNTEM}

\subsection{Materyal}

Çalıșmanın nihai hedefi, Erzincan ilinde, hayvansal atıklardan potansiyel enerji üretim miktarının belirlenerek bu doğrultuda yapılabilecek tesis çalışmalarına yol gösterici olmaktır. Erzincan ilinin hayvansal atık kaynaklı biyogaz potansiyelinin belirlenmesi için ilk adım hayvan sayılarının belirlenmesidir. Bu çerçevede Erzincan Damızlık Sığır Yetiştiricileri Birliği ve Erzincan Gıda, Tarım ve Hayvancılık Müdürlüğü'ne ait veriler araştırmanın temel materyalini oluşturmuştur.

büyükbaş hayvan sayısı ile Merkez ilçesinin oluşturduğu görülmektedir. Erzincan ilindeki toplam küçükbaş hayvan sayıs1 444718 'dir. Bu toplam değerin büyük kısmını oluşturan koyun sayısı, toplam atığın yaklaşık \%90'ını oluşturmaktadır. Küçükbaş hayvan miktarının en yüksek olduğu ilçeler 121644 ile Merkez ilçesi ve ikinci olarak da 92255 değeri ile Tercan İlçesi'dir. Erzincan ilindeki toplam kanatlı hayvan sayısı 729214'tür. Kanatlı hayvan sayısı bakımından Erzincan Merkez ilçesi, 566390 ile başı çekerken, bu değeri 140440'lik hayvan sayısı ile Üzümlü İlçesi takip etmektedir. Öte yandan, Kemaliye İlçesi sadece 220 adet kanatlı hayvan yetiştiriciliği ile en az hayvan sayısına sahip ilçedir. Erzincan ilindeki toplam büyükbaş, küçükbaş ve kanatlı hayvan sayılarının dağılımı Şekil 1 'de görülmektedir.

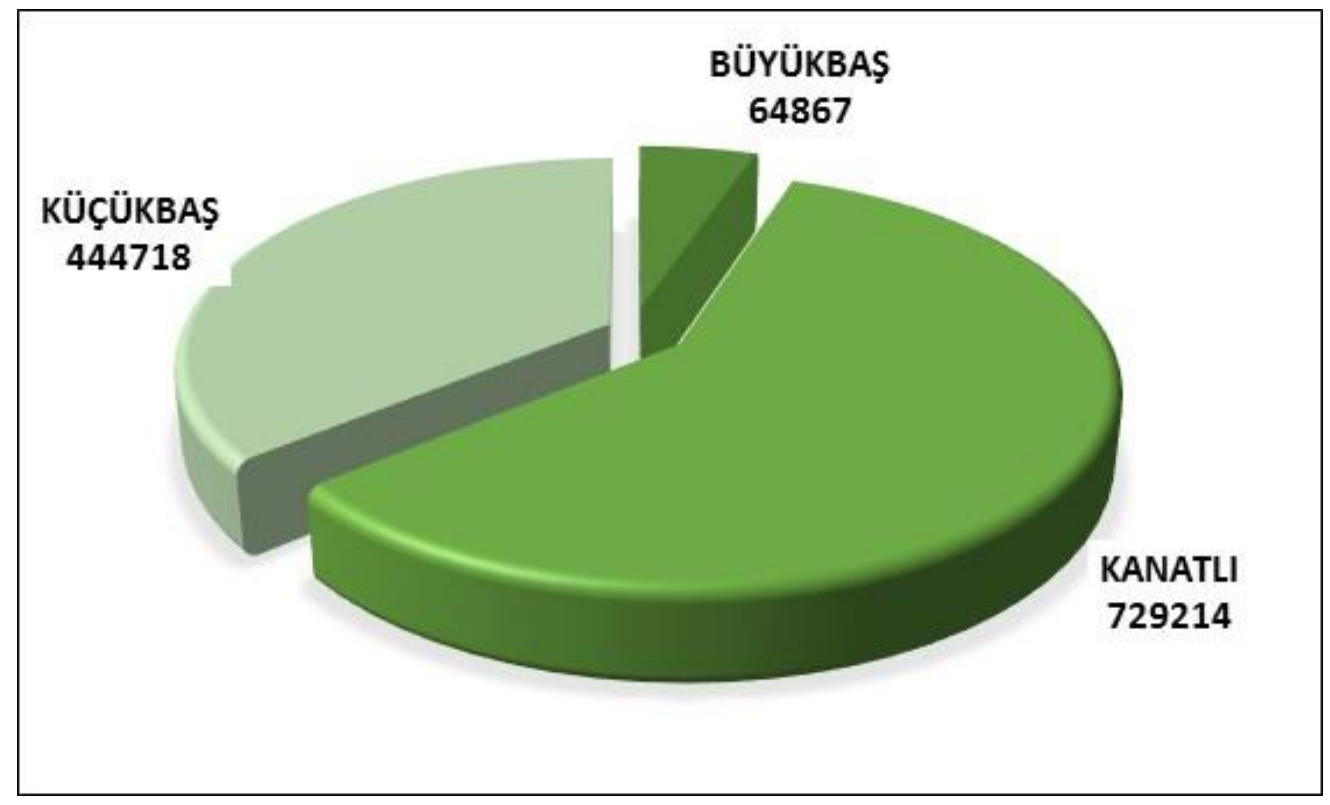

Şekil 1. Toplam büyükbaş, küçükbaş ve kanatlı hayvan sayılarının dağılımı 
Tablo 2. Erzincan Merkez ve ilçelerinde bulunan çiftliklerdeki hayvan sayıları

\begin{tabular}{|l|c|c|c|c|c|c|c|c|}
\hline \multirow{2}{*}{ İLÇELER } & \multirow{2}{*}{$\begin{array}{c}\text { BÜYÜKBAŞ } \\
\mathbf{2 0 1 7} \\
\text { Soy ve Ön Soy } \\
\text { Kütük Birlikte }\end{array}$} & \multicolumn{4}{|c|}{ KANATLI-2015 } & \multicolumn{3}{|c|}{ KÜÇÜKBAŞ-2015 } \\
\cline { 3 - 9 } & Yumurta & Broiler & Diğer* & Toplam & Koyun & Keçi & Toplam \\
\hline MERKEZ & 24646 & 430000 & 135000 & 1390 & 566390 & 119039 & 2605 & 121644 \\
\hline İLİÇ & 533 & 1425 & & 90 & 1515 & 59022 & 9424 & 68446 \\
\hline KEMAH & 1435 & 1500 & & 302 & 1802 & 54586 & 6482 & 61068 \\
\hline OTLUKBELI & 2363 & 3400 & & 175 & 3575 & 2523 & 258 & 2781 \\
\hline TERCAN & 15222 & 5497 & & 2465 & 7962 & 87256 & 4999 & 92255 \\
\hline REFAHIYE & 6208 & 3000 & & 560 & 3560 & 3457 & 1513 & 4970 \\
\hline KEMALIYE & 324 & 200 & & 20 & 220 & 14125 & 14349 & 28474 \\
\hline ÜZÜMLÜ & 5213 & 750 & 139500 & 190 & 140440 & 40509 & 800 & 41309 \\
\hline ÇAYIRLI & 8923 & 3000 & & 750 & 3750 & 21610 & 2161 & 23771 \\
\hline TOPLAM & $\mathbf{6 4 8 6 7}$ & $\mathbf{4 4 8 7 7 2}$ & $\mathbf{2 7 4 5 0 0}$ & $\mathbf{5 9 4 2}$ & $\mathbf{7 2 9 2 1 4}$ & $\mathbf{4 0 2 1 2 7}$ & $\mathbf{4 2 5 9 1}$ & $\mathbf{4 4 4 7 1 8}$ \\
\hline
\end{tabular}

*Diğer; Ördek, hindi ve kaz sayılarının toplamını vermektedir.

\subsection{Yöntem}

\subsubsection{Bölgedeki atık miktarının belirlenmesi}

Bölgedeki hayvansal atık miktarları, bu çalışmada belirtilmiş olan güncel hayvan sayısı ve yapılan günlük hayvansal atık miktar kabulleri göz önüne alınarak hesaplanmıștır. Erzincan ili hayvancılık sektöründe, çeşitli hayvan tiplerine göre karakterizasyon ve günlük hayvansal atık miktarıyla ilgili herhangi bir çalışma yapılmadığı tespit edilmiştir. Bu nedenle, Erzincan il Gıda, Tarım ve Hayvancılık Müdürlüğü yetkilileri ve hayvancılı işletme sahipleri ile görüşmeler gerçekleştirilerek Erzincan ili ortalama büyükbaş canlı hayvan ağırlığı $425 \mathrm{~kg}$ olarak kabul edilmiştir. Terminolojik açıdan bakıldığında hayvan atıkları, kesimhane atıkları dışında kalan hayvan dışkılarından oluşan atığı ifade etmektedir. Büyükbaş hayvanların canlı ağırlığına bağlı olarak üretilebilecek günlük yaş gübre miktarı, canlı ağırlığının \%5-10'u kadardır [18]. Hesaplamalarda \%7 kabulü yapılarak günlük atık miktarı belirlenmiştir. Küçükbaş ve kanatlı hayvanlarda ise Türkiye hayvancılık sektöründeki günlük atık miktarları ve özellikleri kullanılmıştır.

Hayvanların ahırda kalma süreleri, süt sığırı için \%65, et Sığırı için \%25, kanatlı hayvanlar için \%99 ve küçükbaş hayvanlar için \%13 olmaktadır $[19,20]$. Bu nedenle hesaplamalarda ahırda kalma süresi göz önüne alınarak atığın elde edilebilirlik oranı; büyükbaş hayvanlar için $\% 50$, küçükbaş hayvanlar için \%13 ve kanatlı hayvanlar için \%99 olarak seçilmiştir. Hesaplamalarda kullanılmak üzere hayvansal atık tipine bağl1, katı madde, organik katı madde içeriği ve biyogaz üretim potansiyeline ilişkin yapılan kabuller Tablo 3'de özetlenmiştir.

Tablo 3. Atık miktar kabulleri

\begin{tabular}{|c|c|c|}
\hline \multicolumn{1}{|c|}{ Hayvan Tipi } & $\begin{array}{c}\text { Atık Miktarı } \\
\text { kg atık/hayvan*gün }\end{array}$ & Kaynaklar \\
\hline Büyükbaş Hayvanlar & 29.75 & {$[18]$} \\
\hline $\begin{array}{l}\text { Küçükbaş Hayvanlar } \\
\text { Koyun ve Keçi }\end{array}$ & 2 & {$[21]$} \\
\hline Kanatlı (Kümes) Hayvanlar & & {$[22]$} \\
\hline Broiler Tavuk & 0.19 & {$[22]$} \\
\hline Yumurta Tavuğu & 0.13 & {$[23]$} \\
\hline Hindi-Kaz-Ördek & 0.07 & \\
\hline
\end{tabular}

Toplam atık miktarları, güncel hayvan sayıları ile Tablo 3'de verilmiş olan kabullere bağlı olarak, ton.atık/yıl olarak hesaplanmıştır. Bu hesaplamalar çerçevesinde elde edilen yıllık hayvan atık miktarları Tablo 4'te sunulmuştur. 
Tablo 4. Hayvan atık miktarları

\begin{tabular}{|l|c|c|c|c|}
\hline \multicolumn{1}{|c|}{ İLÇELER } & $\begin{array}{c}\text { Büyükbaş Atık } \\
\text { Miktarı (ton/yıl) }\end{array}$ & $\begin{array}{c}\text { Kanatlı Atık } \\
\text { Miktarı (ton/yıl) }\end{array}$ & $\begin{array}{c}\text { Küçükbaş } \\
\text { Atık Miktarı (ton/yıl) }\end{array}$ & $\begin{array}{c}\text { Toplam Atık } \\
\text { Miktarı (ton/yıl) }\end{array}$ \\
\hline MERKEZ & 133812 & 29503 & 11544 & 174859 \\
\hline İLİÇ & 2894 & 69 & 6496 & 9459 \\
\hline KEMAH & 7791 & 78 & 5795 & 13664 \\
\hline OTLUKBELI & 12830 & 164 & 264 & 91722 \\
\hline TERCAN & 82646 & 321 & 8755 & 34333 \\
\hline REFAHIYE & 33706 & 155 & 2702 & 4471 \\
\hline KEMALIYE & 1759 & 10 & 3920 & 41841 \\
\hline ÜZÜMLÜ & 28303 & 9618 & 2256 & 50862 \\
\hline ÇAYIRLI & 48446 & 160 & $\mathbf{4 2 2 0 4}$ & $\mathbf{4 3 4 4 6 9}$ \\
\hline TOPLAM & $\mathbf{3 5 2 1 8 7}$ & $\mathbf{4 0 0 7 8}$ & & \\
\hline
\end{tabular}

Hayvan sayıları ve türlerine bağlı olarak oluşan atık miktarları incelendiğinde en fazla atığı büyükbaş hayvanların oluşturduğu görülmektedir. Yıllık toplam değerlere göre oluşan atık miktarları büyükten küçüğe; 352187 ton atık/yıl ile büyükbaş hayvanlar, 42204 ton.atık/yıl ile küçükbaş hayvanlar ve 40078 ton atık/yıl kanatlı hayvanlar şeklinde siralanabilir. Hayvan türlerinden kaynaklanan atık miktarlarının yüzdelik genel dağılımı Şekil 4'te verilmiştir. Büyükbaş hayvanlardan elde edilen atık miktarı, toplam atık miktarı içerisinde $\% 81$ ile en büyük kısmı oluşturmaktadır.

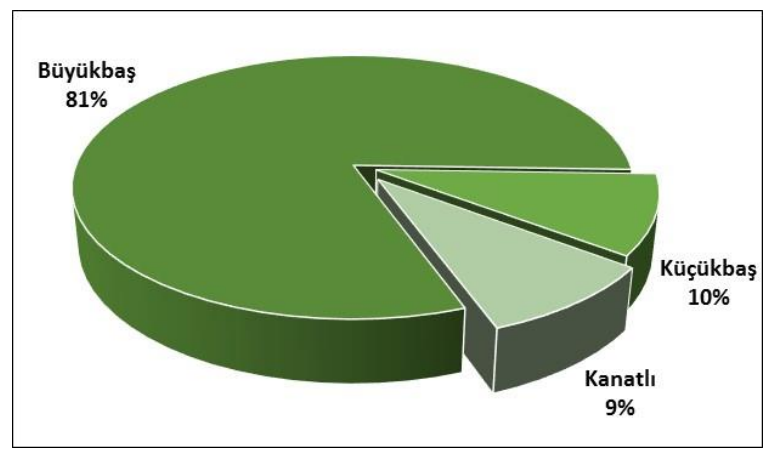

Şekil 4. Hayvan atıklarının kaynağına göre yüzdelik dağılımı
Büyükbaş, küçükbaş ve kanatlı hayvan atık miktarlarının ilçelere göre dağılımı incelendiğinde, büyükbaş kaynaklı en yüksek atık miktarının yine büyükbaş hayvan sayısı en fazla olan Erzincan Merkez İlçesi’nde olduğu görülmektedir. Merkez ilçeyi Tercan, Çayırlı ve Refahiye ilçeleri izlemektedir. Küçükbaş hayvan atık miktarının yıllık olarak en fazla olduğu ilçeler, Merkez ile Tercan ilçeleridir. Aynı zamanda bu ilçeler, hayvan sayısının da en fazla olduğu ilçelerdir. Kanatlı hayvan atık miktarının en fazla olduğu ilçeler, Merkez ile Üzümlü ilçeleridir. Bu ilçelerdeki atık miktarının fazla olmasının nedeni ise yoğun bir şekilde broiler ve yumurta tavukçuluğu yapılıyor olmasıdır.

Büyükbaş, küçükbaş ve kanatlı hayvanlardan elde edilen atık miktarının Erzincan genelindeki toplam değeri, 434469 ton/yıl olarak hesaplanmıştır. İlçe bazlı hayvan atık dağılımı incelendiğinde en fazla atığın 174860 ton/yıl ile Merkez ilçede gerçekleştiği hesaplanmıştır. Merkez ilçede büyükbaş hayvancılığın yaygın olması dolayısıyla bu ilçeden elde edilen büyükbaş kaynaklı atık miktarı değeri de yüksek olmaktadır. Merkez'den sonra 91722 ton/yıl ile Tercan, 50862 ton/yıl ile Çayırlı, 41841 ton/yıl ile Üzümlü, 34332 ton/yıl ile Refahiye, 13665 ton/y1l ile Kemah, 13258 ton/y1l ile Otlukbeli, 9459 ton/yıl ile İliç ve 4471 ton/y1l ile Kemaliye gelmektedir ( Şekil 5).

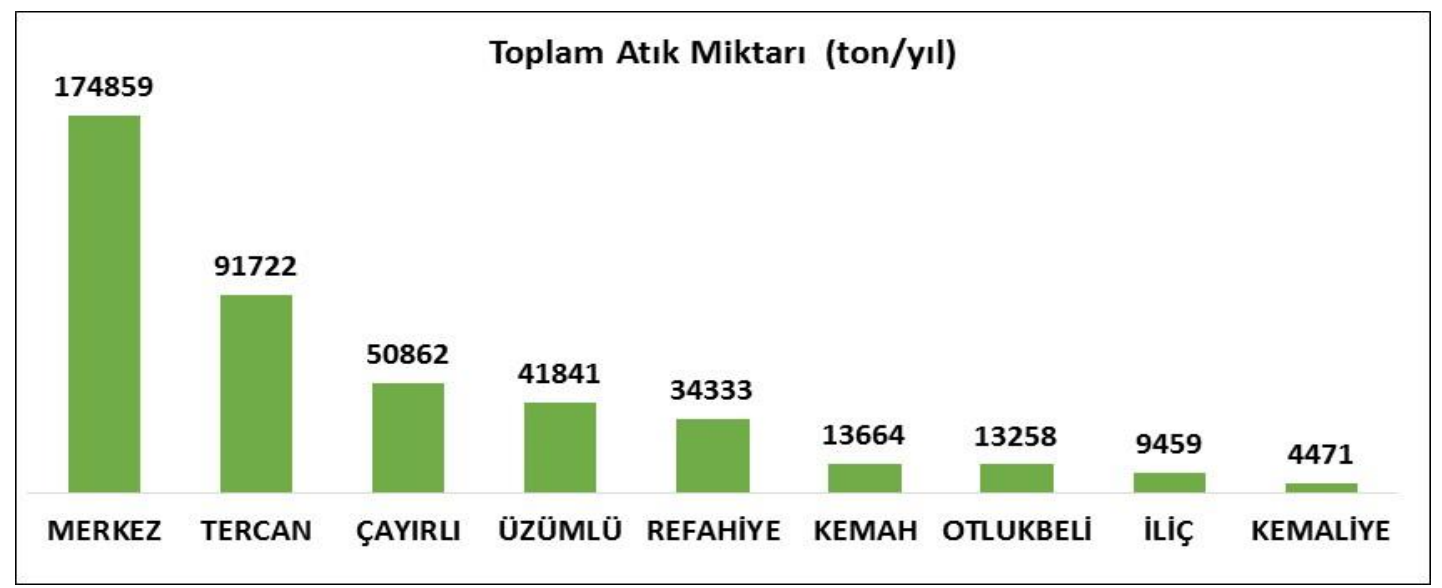

Şekil 5. Toplam hayvan atık miktarlarının ilçe bazlı dağılımı 
Hayvansal atıkların enerji üretim potansiyelleri, bu çalışma kapsamında incelenmiştir. Her hayvansal atık tipi, kimyasal ve fiziksel özelliklerine bağlı olarak değișen farklı enerji potansiyellerine sahiptir. Tablo 5 'te hayvan atıklarının kabul edilen özellikleri verilmiştir.

Tablo 5. Hayvan atıklarının kabul edilen özellikleri [24]

\begin{tabular}{|c|c|c|c|}
\hline Atık Türü & $\begin{array}{c}\text { K.M. } \\
\text { (Katı Madde) }\end{array}$ & $\begin{array}{c}\text { O.K.M. } \\
\text { (Organik Katı Madde) }\end{array}$ & $\begin{array}{c}\text { Biyogaz Potansiyeli } \\
\text { (m } \mathbf{3} / \text { ton O.K.M.) }\end{array}$ \\
\hline Büyükbaş havyan atığı & $14.5 \%$ & $77.5 \%$ & 250 \\
\hline Kanatı hayvan atığı & $28 \%$ & $80 \%$ & 400 \\
\hline Küçükbaş hayvan atığı & $30 \%$ & $80 \%$ & 200 \\
\hline
\end{tabular}

Potansiyel hesaplamalarında kullanılmak üzere temel alınan doğalgaz, kömür, gübre ve elektrik birim fiyatları, kömür, biyogaz ile doğalgazın kalorifik değerleri ve bunlara ek olarak kojenerasyon verimi, Dolar ve Euro merkez bankası efektif alış fiyatları Tablo 6'da verilmiştir.

Tablo 6. Potansiyel hesaplamalarında yapılan kabuller [25, 26]

\begin{tabular}{|l|c|c|}
\hline PARAMETRE & DEĞER & BİRIM \\
\hline $1 \mathrm{~m}^{3}$ biyogaz & 0.65 & $\mathrm{~m}^{3} \mathrm{CH}_{4}$ \\
\hline Biyogaz alt ısıl değeri & 5.837 & $\mathrm{kwh} / \mathrm{m}^{3}$ \\
\hline Kojenerasyon Elektrik Üretim Verimi & $42 \%$ & - \\
\hline Kojenerasyon Termal Verim & $46 \%$ & - \\
\hline Doğalgaz birim fiyatı & 0.60 & $\mathrm{TL} / \mathrm{m}^{3}$ doğalgaz \\
\hline Kömür birim fiyatı & 150 & $\mathrm{TL} /$ ton kömür \\
\hline Elektrik birim fiyatı & 0.39 & $\mathrm{TL} / \mathrm{kWh}$ elektrik \\
\hline Merkez Bankası Efektif Alış (Ocak, 2016) & 2.94 & USD/TRY \\
\hline Merkez Bankası Efektif Alış (Ocak, 2016) & 3.20 & EUR/TRY \\
\hline
\end{tabular}

\section{BULGULAR}

\subsection{Biyogaz Üretim Potansiyeli}

Tablo 7. Erzincan ili toplam biyogaz üretim potansiyeli

\begin{tabular}{|c|c|c|c|c|c|c|c|c|c|c|}
\hline İLÇELER & $\begin{array}{c}\text { Büyükbaş } \\
\text { Atık } \\
\text { Miktarı } \\
\text { (ton/yıl) }\end{array}$ & $\begin{array}{c}\text { Kanatlı } \\
\text { Attk } \\
\text { Miktarı } \\
\text { (ton/yil) }\end{array}$ & $\begin{array}{c}\text { Küçükbaş } \\
\text { Atık } \\
\text { Miktarı } \\
\text { (ton/yıl) }\end{array}$ & $\begin{array}{c}\text { Toplam } \\
\text { Atık } \\
\text { Miktarı } \\
\text { (ton/yıl) }\end{array}$ & $\begin{array}{c}\text { Biyogaz } \\
\text { Potansiyeli } \\
\text { (m3/yl) }\end{array}$ & $\begin{array}{c}\text { Metan } \\
\text { Potansiyel } \\
\text { i (m3/yl) }\end{array}$ & $\begin{array}{c}\text { Elektrik } \\
\text { Üretimi } \\
\left(\mathbf{k W h} \mathbf{h}_{\mathrm{e}} / \mathbf{y l}\right)\end{array}$ & $\begin{array}{l}\text { Isı Üretimi } \\
\text { (kcal/yıl) }\end{array}$ & $\begin{array}{c}\text { Kurulu } \\
\text { Güç } \\
(\mathbf{k W})\end{array}$ & $\begin{array}{c}\text { Ton } \\
\text { Eşdeğer } \\
\text { Petrol } \\
\text { (TEP / yıl) }\end{array}$ \\
\hline MERKEZ & 133812 & 29503 & 11544 & 174860 & 6956896 & 4521982 & 17055108 & 16064863228 & 1947 & 1466,74 \\
\hline İLİÇ & 2894 & 69 & 6496 & 9459 & 399286 & 259536 & 978866 & 922031964 & 112 & 84,18 \\
\hline КЕМАН & 7791 & 78 & 5795 & 13665 & 504058 & 327637 & 1235717 & 1163969851 & 141 & 106,27 \\
\hline OTLUKBELİ & 12830 & 164 & 264 & 13258 & 387807 & 252075 & 950725 & 895524361 & 109 & 81,76 \\
\hline TERCAN & 82646 & 321 & 8755 & 91722 & 2770798 & 1801019 & 6792722 & 6398326909 & 775 & 584,17 \\
\hline REFAHIYE & 33706 & 155 & 472 & 34332 & 983451 & 639243 & 2410970 & 2270985307 & 275 & 207,34 \\
\hline KEMALIYE & 1759 & 10 & 2702 & 4471 & 180012 & 117008 & 441307 & 415683943 & 50 & 37,95 \\
\hline ÜZÜMLÜ & 28303 & 9618 & 3920 & 41841 & 1845056 & 1199287 & 4523229 & 4260603728 & 516 & 389,00 \\
\hline ÇAYIRLI & 48446 & 160 & 2256 & 50862 & 1483647 & 964371 & 3637220 & 3426037822 & 415 & 312,80 \\
\hline TOPLAM & 352187 & 40078 & 42204 & 434469 & 15511011 & $\begin{array}{c}1008215 \\
7\end{array}$ & 38025864 & 35818027112 & 4341 & 3270,22 \\
\hline
\end{tabular}

Erzincan İlinin hayvansal atık miktarı ve bu atıklardan elde edilecek olan biyogaz enerjisi potansiyelini belirlemek amacıyla, bölgede yer alan işletmelerde kayıtlı olan hayvan sayılarının ilçe bazında yıllık hayvansal atık üretim miktarı ve bu atıklardan elde edilebilecek biyogaz ve metan potansiyeli hesaplamaları yapılmıştır. Büyükbaş, küçükbaş ve kanatlı hayvan sayıları baz alınarak bu atıkların değerlendirilmesiyle elde edilebilecek biyogaz, metan, elektrik ve 1sı miktarlarının ilçe bazında dağılımı Tablo 7'de sunulmuştur. 
Erzincan ilinin toplam biyogaz potansiyeli $15511011 \mathrm{~m}^{3} / \mathrm{y} 1 \mathrm{l}$ olarak hesaplanmıştır. Biyogaz üretim potansiyeli ilçeler bazında incelendiğinde en yüksek potansiyele sahip ilçenin, $6956896 \mathrm{~m}^{3} / \mathrm{y}$ 1l ile Merkez ilçe olduğu belirlenmiştir. Bunu sırasıyla Tercan, Üzümlü, Çayırlı, Refahiye, Kemah, İliç, Otlukbeli ve Kemaliye izlemektedir. Biyogaz üretim potansiyelinin ilçeler bazında kıyaslanması Şekil 6'da verilmiştir. Üretilen biyogazın saflık derecesi, metan içeriği ile belirlenmektedir. Genel bir yaklaşımla, bir biyogaz tesisinin sorunsuz çalışabilmesi için ürettiği biyogaz, en az \%65 metan içeriğine sahip olmalıdır. Çalışma kapsamında \%65 metan üretileceği kabulü ile Erzincan ilinin yıllık metan üretim potansiyeli $10082157 \mathrm{~m}^{3}$ olarak hesaplanmıştır.

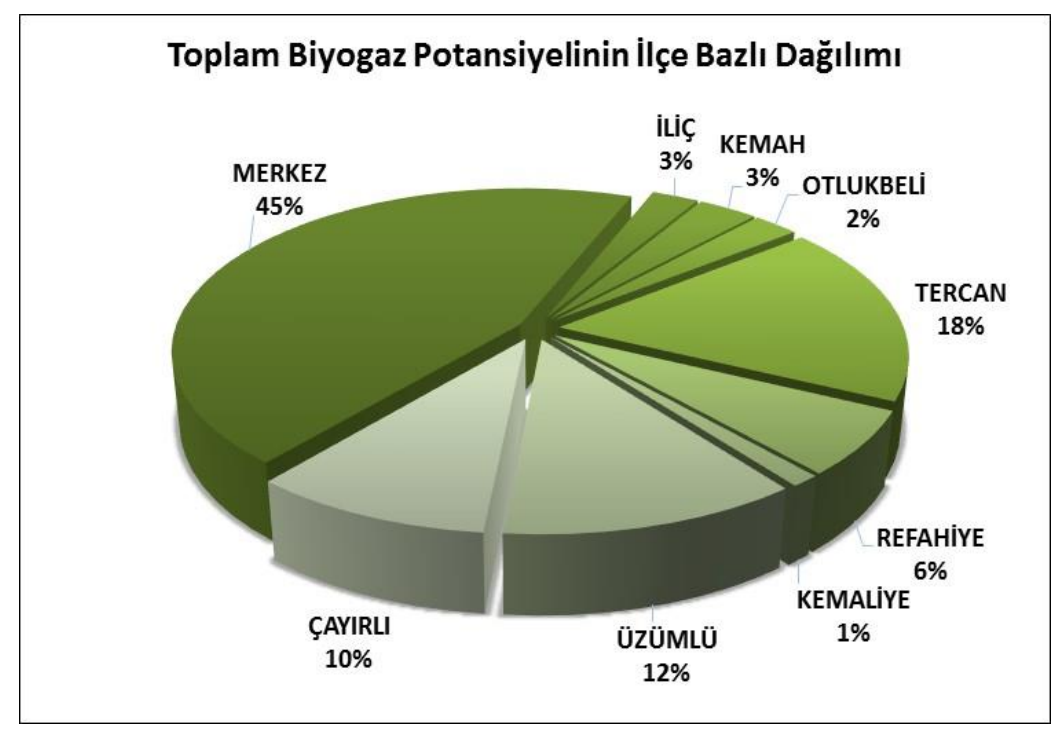

Şekil 6. Erzincan ili toplam biyogaz potansiyelinin ilçe bazlı dağılımı

Erzincan ilinin biyogazdan üretilebilecek yıllık toplam elektrik üretimi potansiyeli $38025864 \mathrm{kWh}_{\mathrm{e}}$ olarak hesaplanmıştır. En yüksek elektrik üretimi biyogaz potansiyelinin de en fazla olduğu Merkez ilçedir. Erzincan ilinde hayvansal atık kaynaklı biyogazdan elektrik üretiminin ilçe bazlı dağılımı Şekil 7'de verilmiştir.

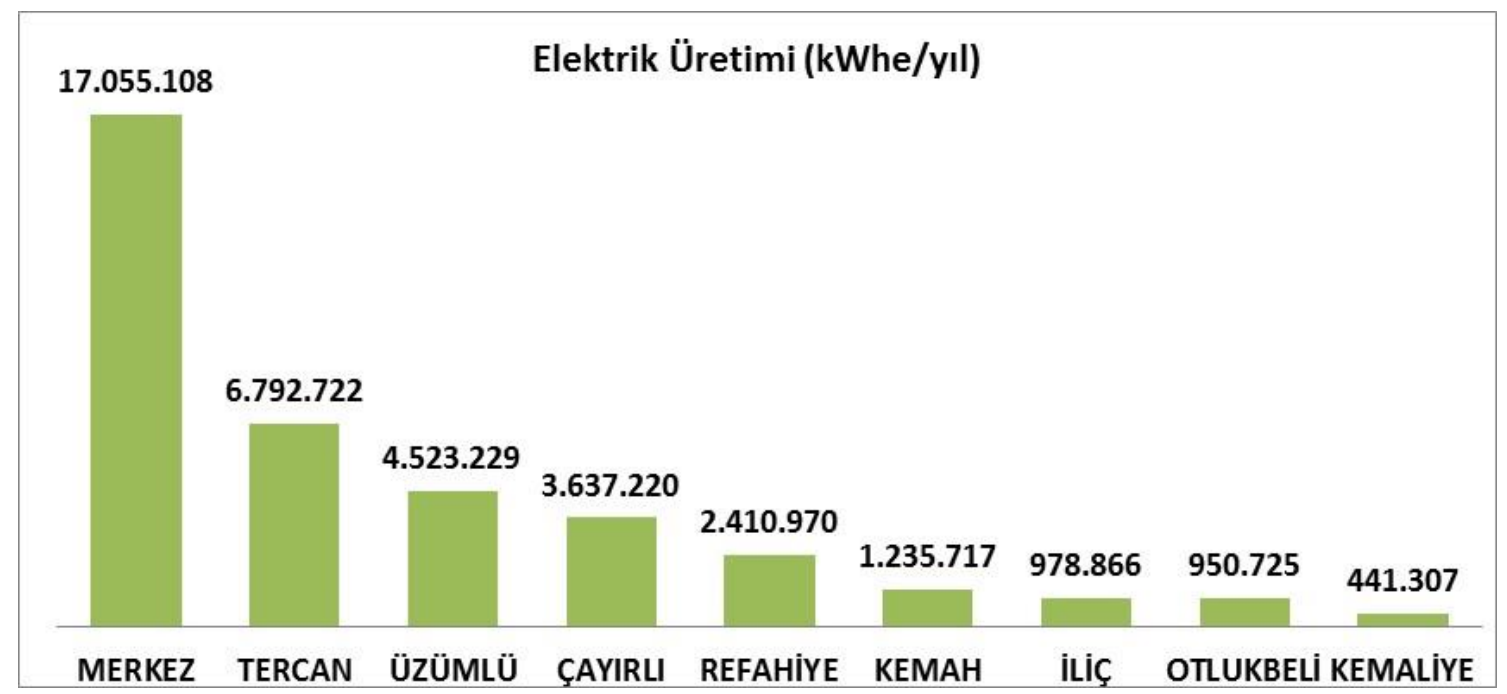

Şekil 7. Erzincan ili toplam biyogaz potansiyelinden elektrik üretimi ilçe dağılımı

Elektrik piyasasında faaliyette bulunan lisans sahibi şirketlerin T.C. Enerji Piyasası Düzenleme Kurumuna sunmuş oldukları bildirimler esas alınarak hazırlanmış olan Eylül/2017 Elektrik Piyasası Sektör Raporu'na göre Erzincan ili elektrik tüketim miktarı 36783,69 MWh olup Türkiye genelinde $\% 0,15$ 'lik orana sahiptir [27].

4 kişilik bir ailenin asgari yaşam standartına göre aylık elektrik tüketimi araştırmalara göre 135 kWh/ay [28] , $230.4 \mathrm{kWh} / \mathrm{ay}$ [29] ve 297.8 $\mathrm{kWh} / \mathrm{ay}$ 'dır [30]. Bu değerler göz önüne alınarak 4 
kişilik bir ailenin asgari yaşam standartına göre ortalama aylık elektrik tüketimi $221 \mathrm{kWh} /$ ay ve y1llık elektrik tüketimi $2652 \mathrm{kWh} / \mathrm{y} 1 \mathrm{l}$ olarak hesaplanmıştır. Çalışmada Erzincan ili için yıllık biyogaz'dan elektrik üretim potansiyeli 38025864 kWh olarak hesaplanmıştır. Bu durumda Erzincan ilinin biyogaz potansiyeli değerlendirildiği takdirde üretilecek enerji yaklaşık 14300 hanenin elektrik ihtiyacını karşılayabilecektir.

Erzincan ilinde hayvansal atık kaynaklı biyogaz üretim potansiyelinden yararlanılarak, 35818027112 $\mathrm{kcal} / \mathrm{y} 1 \mathrm{l}$ atık 1sı üretimi gerçekleştirilebilir. Erzincan ilinde hayvansal atık kaynaklı biyogazdan 1S1 üretiminin ilçe bazlı dağılımı Şekil 8'de verilmiştir.

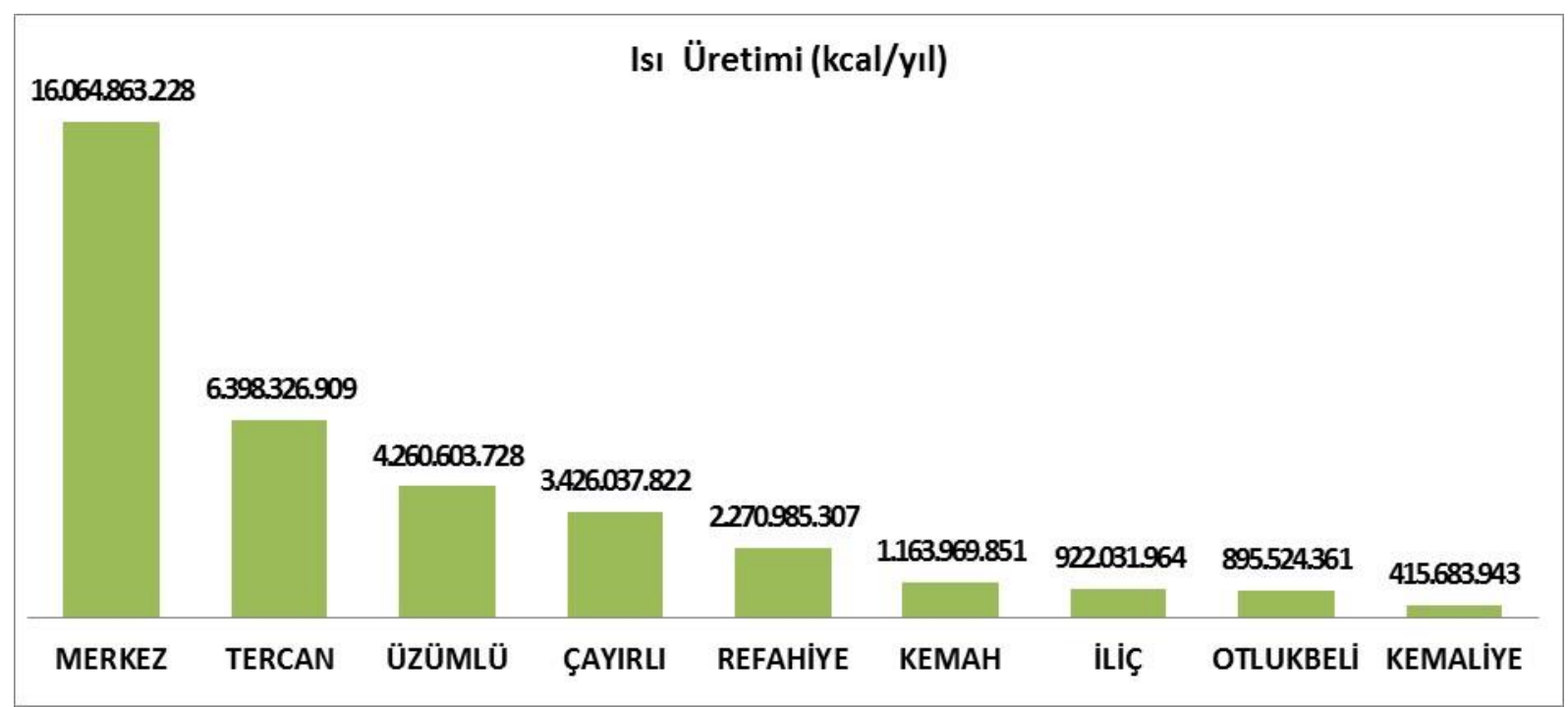

Şekil 8. Erzincan ili toplam biyogaz potansiyelinden 1sı üretimi ilçe bazlı dağılımı

\subsection{Gelir ve Fayda Hesaplamaları}

Erzincan ilinde hayvansal atık kaynaklı biyogaz üretiminin dönüşümü ile elde edilebilecek elektrik ve atık 1S1 kaynaklı faydalar Tablo 8'de verilmiştir.

Tablo 8. Erzincan ili hayvan atıklarının biyogaz tesislerinde kullanılması ile elde edilecek faydalar

\begin{tabular}{|c|c|c|c|c|c|c|}
\hline \multirow{3}{*}{$\begin{array}{l}\text { FAYDA } \\
\text { İLÇELER }\end{array}$} & \multirow{2}{*}{\multicolumn{2}{|c|}{ Elektrik Kaynaklı Fayda }} & \multicolumn{4}{|c|}{ Isıl Kaynaklı Fayda } \\
\hline & & & \multicolumn{2}{|c|}{$\begin{array}{c}\text { Doğalgaz Eşdeğerine } \\
\text { Göre }\end{array}$} & \multicolumn{2}{|c|}{ Kömür Eşdeğerine Göre } \\
\hline & $\underset{(\mathbf{k W h} / \mathbf{y l l})}{\ddot{\text { Uretim }}}$ & $\begin{array}{l}\text { Faydası } \\
\text { (TL/yıl) }\end{array}$ & $\begin{array}{l}\text { Miktar } \\
\left(\mathrm{m}^{3} / \mathbf{y l}\right)\end{array}$ & $\begin{array}{c}\text { Fayda } \\
(\text { TL/yıl) }\end{array}$ & $\begin{array}{c}\text { Miktar } \\
\text { (ton/yıl) }\end{array}$ & $\begin{array}{c}\text { Fayda } \\
(T L / y ı l)\end{array}$ \\
\hline MERKEZ & 17055108 & 6992594 & 1947256 & 1168354 & 5355 & 803243 \\
\hline İLİÇ & 978866 & 401335 & 111761 & 67057 & 307 & 46102 \\
\hline КЕМАН & 1235717 & 506644 & 141087 & 84652 & 388 & 58198 \\
\hline OTLUKBELI & 950725 & 389797 & 108548 & 65129 & 299 & 44776 \\
\hline TERCAN & 6792722 & 2785016 & 775555 & 465333 & 2133 & 319916 \\
\hline REFAHIYE & 2410970 & 988498 & 275271 & 165163 & 757 & 113549 \\
\hline KEMALIYYE & 441307 & 180936 & 50386 & 30232 & 139 & 20784 \\
\hline ÜZÜMLÜ & 4523229 & 1854524 & 516437 & 309862 & 1420 & 213030 \\
\hline ÇAYIRLI & 3637220 & 1491260 & 415277 & 249166 & 1142 & 171302 \\
\hline TOPLAM & 38025864 & 15590604 & 4341579 & 2604947 & 11939 & 1790901 \\
\hline
\end{tabular}


Erzincan ilinde hayvansal atıkların biyogaz santrallerinde değerlendirilmesiyle, elektrik kaynaklı olarak yıllık 15590604 TL fayda sağlanması mümkün olacaktır. Atık 1sıdan sağlanabilecek fayda kömür ve doğalgaz eşdeğerine göre hesaplanmıştır. Elde edilecek atık 1s1, doğalgaz eşdeğeri olarak kabul edildiğinde sağlanacak fayda y1llık 2604947 TL olacaktır. Kömür eşdeğeri olarak kabul edildiğinde, kömürün daha düşük maliyetli bir yakıt olması sebebiyle yıllık sağlanacak fayda 1790901 TL olacaktır.

\section{DEĞERLENDİRME VE SONUÇ}

Türkiye'nin bölgesel ve genel biyogaz üretim potansiyelini değerlendirmek için birçok çalışma yapılmıştır. Bununla birlikte, bu çalışmalar çeşitli biyogaz kaynaklarının enerji potansiyeline odaklanmıştır [8, 16, 31-33]. Türkiye ekonomisinin esasen tarım ve hayvancılık alanlarında faaliyet gösteren doğu şehirlerinden biri olan Erzincan'ın biyogaz potansiyelini net veriler üzerinden ortaya çıkartan bir çalışmaya rastlanamamıştır. Literatürdeki benzer çalışmalarda çoğunlukla materyal olarak Türkiye İstatistik Kurumu'nun (TUİK) verileri kullanılmaktadır $(16,27,33,34]$.

Erzincan ilinde büyükbaş, küçükbaş ve kanatlı hayvan çiftliklerinde oluşan hayvansal atıklar, herhangi bir atık yönetimine dâhil edilmeden, doğrudan belediyenin çöp depolama sahalarına gönderilmekte veya tarım alanlarında toprağın altına karıştırılarak gübrelemede kullanım amacıyla bertaraf edilmektedir. Bu uygulamalar, çevre ve hava kirliliği, kimyasal ve biyolojik bozunmalar sonucu atıklardan sızan sızıntı sularının, toprağa ve yeraltı sularına karışmasıyla çevre ve insan sağlığı bakımindan son derece ciddi problemler oluşturabilmektedir. Tarım alanlarının verimsiz ve kullanılamaz hale gelmesine de sebebiyet verirken, temiz su kaynaklarıyla doğrudan doğruya bağlantılı olan yer altı sularını da kirletmektedir. Bunun yanısıra yüksek enerji üretim potansiyeline sahip olan bu hayvansal atıkların, değerlendirilmeden bertaraf edilmesi, milli enerji kaynaklarımızın bir kaybidir.

$\mathrm{Bu}$ sebeple Erzincan ilinde değerlendirilmeyen atıkların ekonomiye kazandırılması yönünde, Erzincan Merkez ve ilçelerinde bulunan hayvancilık işletmelerinden kaynaklı atıkların, biyogaz enerjisi potansiyelinin belirlenmesi amaçlanmıştır. $\mathrm{Bu}$ potansiyelin belirlenmesinde hayvan sayıları ile ilgili veriler saha çalışmalarından, birliklerden, kamu kurumları ve yerel enstitülerden alınmıştır. Çalışmanın özgünlüğü kayıtlı net veriler üzerinden çalışılmış olmasıdır. Elde edilen verilerden hayvansal atık miktarları ve bu atıkların biyogaz potansiyeli belirlenerek bölgedeki atıkların elektrik ve 1sı enerjisi potansiyeli hesaplanmıştır.

Buna göre Erzincan ilinde toplam büyükbaş hayvan sayıs1 64867, küçükbaş hayvan sayısı 444718, kanatlı hayvan sayısı ise 729214'tür. Çalışmada elde edilen bu sayısal verilere göre, Erzincan genelindeki toplam atık miktarı ise 434469 ton/yıl olarak hesaplanmıştır. $\mathrm{Bu}$ atık miktarlarına göre Erzincan ilinin toplam biyogaz potansiyeli $15511011 \mathrm{~m}^{3} / \mathrm{y} 1 \mathrm{l}$ olarak hesaplanmıştır. Biyogazdan üretilebilecek y1llık toplam elektrik üretimi potansiyel 38025864 kWhe'dır. Ayrıca aynı kaynaklı biyogaz üretim potansiyelinden yararlanilarak ilde 35818027112 kcal/y1l 1s1 enerjisi üretimi de elde edilebilecektir.

$\mathrm{Bu}$ durumda y1llı toplam elektrik üretimi potansiyeli $38025864 \mathrm{kWh}_{\mathrm{e}}$ olan Erzincan ilinin biyogaz potansiyeli değerlendirildiği takdirde üretilecek enerji yaklaşık 14300 hanenin elektrik ihtiyacını karşılayabilecektir.

Erzincan'da yeter sayıda hayvansal atığın bulunduğu ve bu atıkların değerlendirilmesi yoluyla elektrik kaynaklı olarak y1llı 15590604 TL fayda sağlanacağı görülmektedir. Is1 enerjisinden sağlanacak y1llık fayda kömür ve doğalgaz ile mukayese edildiğinde, doğalgaz eşdeğerine göre 2604947 TL iken daha düşük maliyetli kömüre göre ise 1790901 TL olacaktır.

Çalışmada bölgedeki büyükbaş hayvansal atıkların \%50'si, küçükbaş hayvan atıklarının \%13'ü, kanatlı hayvan atıklarının ise \%99'unun elde edilebilir, tüm bu hayvansal atıkların eşit parçalanma kapasitesi ile biyolojik olarak parçalanabilir olduğu öngörüsüyle yapılan hesaplamalar sonucunda, biyogaz kaynaklı elektrik kurulu gücü bakımından Erzincan'ın 4.3 MW'lık bir potansiyel barındırdığı, biyogaz ve enerji üretimi değerleri açısından da kayda değer bir nitelik taşıdığı görülmektedir.

Sonuç olarak Erzincan özelinde hayvansal atıkların bertaraf edilmesinde biyogaz teknolojisinin katma değeri yüksek önemli bir yöntem olduğu görülmektedir. İlerleyen y1llarda, sektörel gelişmelere bağlı olarak, Erzincan ve ilçelerinde hayvansal atıklarda artış yaşanacaktır. Mevcut geleneksel uygulamaların devam etmesi durumunda ise hayvansal atık kokusu, sera gazı salınımları nedeniyle azalan hava kalitesi, hijyen, atıkların gömülmesi ve depolama için uygun alan bulamama gibi sorunlar gittikçe artacak ve finansal açıdan yük oluşturmaya başlayacaktır. Oysa biyogaz tesislerinde atıkların bertaraf edilmesiyle çevresel ve mali problemler çözülecek, aynı zamanda kırsal kalkınma sağlanarak, hayvansal atıklar yenilenebilir enerji kaynağı olarak değerlendirilebilecektir. 
Erzincan ili ve ilçelerinde büyükbaş, küçükbaş ve kanatlı hayvan sayıları, hayvansal atık miktarı, bu atıklardan elde edilebilecek biyogaz, elektrik ve is1 enerjisi üretim potansiyelleri, hayvansal atık kaynaklı biyogaz yatırımları için umut vaat etmektedir. $\mathrm{Bu}$ durum biyogaz tesislerinin kurulumunu gerektirirken, tesis için olası potansiyel de bölgede mevcuttur.

Yapılan bu çalışmanın, Erzincan ilinde tesis edilecek biyogaz tesislerinin planlanmasında yol gösterici bir rehber olmasının yanı sıra büyükbaş, küçükbaş ve kanatlı hayvanlardan kaynaklı atıklardan enerji elde edilmesiyle sürdürülebilir bir atık yönetim modeli oluşturması hedeflenmektedir. İlerideki çalışmalarda mevcut veriler kullanılarak Erzincan ilinde bulunan hayvansal atıkların toplanarak bir biyogaz tesisine aktarılmak istenmesi durumunda hangi bölgelerde biyogaz tesislerinin kurulabileceği çalışması üzerine odaklanılabilir.

\section{REFERANSLAR}

[1] P. Abdeshahian, J. S. Lim, W. S. Ho, H., Hashim ve C. T. Lee, "Potential of biogas production from farm animal waste in Malaysia", Renewable and Sustainable Energy Reviews, 60, 714-723, 2016.

[2] A.G. Olabi, “100\% sustainable energy”, Editorial Energy, 77, pp. 1-5, 2014.

[3] H. Lund Connolly ve B.V. Mathiesen, "Smart Energy Europe: The technical and economic impact of one potential $100 \%$ renewable energy scenario for the European Union", Renewable and Sustainable Energy Reviews, 60, pp. 1634-1653, 2016.

[4] L.E.N. Ekpeni, K.Y. Benyounis, F.N. Ekpeni, J. Stokes ve A.G. Olabi, "Energy Diversity through Renewable Energy Source (RES) - A Case Study of Biomass", Energy Procedia, 61, pp. 1740-1747, 2014.

[5] N. Saracoglu, "The importance of bioenergy and energy forestry for Turkey", Zero Emission Power Generation Workshop, TUBITAK, Turkey, 16th to 18th April 2007.

[6] S. Bilgen, S. Keleş, A. Kaygusuz, A. Sarı ve K. Kaygusuz, "Global warming and renewable energy sources for sustainable development: a case study in Turkey", Renewable and Sustainable Energy Reviews, 12, pp. 372-396, 2008.

[7] K. Kaygusuz, S. Keleş”Journal of Engineering Research and Applied Science "Volume 1(1), June 2012, pp 34-43.
[8] E. Toklu, "Biomass energy potential and utilization in Turkey", Renewable Energy, Volume 107, pp. 235-244, July 2017.

[9] TMMOB Makina Mühendisleri Odas1, "Yenilenebilir Enerji Kaynakları", Oda Raporu, Yayın No: MMO/2008/479, Ankara, 2008.

[10] J. Dai, B. Chen, T. Hayat, A. Alsaedi, ve B. Ahmad, "Sustainability-based economic and ecological evaluation of a rural biogas-linked agroecosystem", Renewable and Sustainable Energy Reviews, 41, 347-355, 2015.

[11] M. Öztürk, "Hayvan Gübresinden Biogaz Üretimi”, Çevre ve Orman Bakanlığı, Ankara, 2005.

[12] S. Rasi, A. Veijaneny ve J. Rintala, "Trace compounds of biogas from different biogas production plants", Energy, 32, pp. 1375-1380, 2007.

[13] R. Kadam ve N.L. Panwar, "Recent advancement in biogas enrichment and its applications", Renewable and Sustainable Energy Reviews, 73, pp. 892-903, June 2017.

[14] G.H. Çağlayan ve N. Nacar Koçer, "Muş İlinde Hayvan Potansiyelinin Değerlendirilerek Biyogaz Üretiminin Araştırılması", Muş Alparslan Üniversitesi Fen Bilimleri Dergisi, cilt 2, say1 1, Haziran 2014.

[15] M. Öztürk, ve Y. E. Yüksel, "Energy structure of Turkey for sustainable development", Renewable and Sustainable Energy Reviews, 53, 1259-1272, 2016.

[16] B. Özer, "Biogas Energy Opportunity of Ardahan City of Turkey", Energy, In Press, Accepted Manuscript, Available online 25 July 2017.

[17] S. Achinas, V. Achinas ve G.J.W. Euverink, “A Technological Overview of Biogas Production from Biowaste", Engineering, Volume 3, Issue 3, pp. 299 307, June 2017

[18] D. Kaya ve H.H. Öztürk, Biyogaz Teknolojisi Üretim-Kullanım-Projeleme, İstanbul, Umuttepe Yayınları, 2012.

[19] A. Onurbaş Avcıoğlu, "Tavukçuluk Atıklarından Biyogaz Eldesi Ve Kullanım Olanakları", Tavuk Gübresinin İşlenerek Değerlendirilmesi Semineri, Hollanda Kraliyet Ankara Büyükelçiliği Tarım Müşavirliği ve BESDBİR, Ankara, 27 Mayıs 2010. 
[20] İ. Yokuş, “Sivas İlindeki Hayvansal Atıkların Biyogaz Potansiyeli", Yüksek Lisans Tezi, Ankara Üniversitesi Fen Bilimleri Enstitüsü, Ankara, 2011.

[21] F. Berkes ve M.B. Kışlalıŏlu, Çevre ve Ekoloji, İstanbul, 4.Basım, Remzi Kitabevi, 1993.

[22] Suluova Biyogaz Tesisinin Teknik-Ekonomik Esaslarına İlişkin Rapor, T.C Çevre ve Şehircilik Bakanlığı Türk-Alman Biyogaz Projesi, URL:http://www.biyogaz.web.tr/files/docs/fizibilite _calismasi_suluova_(h.berg).pdf (Erişim zamanı; 11 Ağustos, 2017).

[23] N. Koçer Nacar, C. Öner ve İ. Sugözü, "Türkiye'de Hayvancılık Potansiyeli Ve Biyogaz Üretimi”, Firat Üniversitesi Doğu Anadolu Araştırmaları Merkezi, 17-20, 2006.

[24] D. Deublein, ve A. Steinhauser, "Biogas from Waste and Renewable Resources", WILEY-VCH Verlag, Germany, 57-77, 2008.

[25] M. Gustavsson, "Biogas Technology-Solution in Search of Its Problem A Study of Small-Scale Rural Technology Introduction and Integration", Göteborg University, Göteborg, 2000.

[26] Türkiye Cumhuriyet Merkez Bankası, "Gösterge Niteliğindeki Merkez Bankası Kurları", URL:http://www.tcmb.gov.tr/wps/wcm/connect/TC $\mathrm{MB}+\mathrm{TR} / \mathrm{TCMB}+\mathrm{TR} / \mathrm{Main}+\mathrm{Menu} /$ Istatistikler/Dovi $\mathrm{z}+$ Kurlari/Gosterge+Niteligindeki+Merkez+Bankas i+Kurlarii (Erişim zamanı; 11 Ağustos, 2017).

[27] Elektrik Piyasası Sektör Raporu Eylü1/2017, T.C. Enerji Piyasası Düzenleme Kurumu, Strateji
Geliştirme Dairesi Başkanlığı, Ankara, 2017. file://C:/Users/hp/Documents/Downloads/Elektrik_ Eylul_2017raporu_Web_V2.pdf (Erişim zamanı; 29 Aralık, 2017).

[28] F. DİNÇER, “Türkiye'de Güneş Enerjisinden Elektrik Üretimi Potansiyeli - Ekonomik Analizi ve AB Ülkeleri ile Karşılaştırmalı Değerlendirme", KSU Mühendislik Dergisi, 14(1), (8-17), 2011.

[29] B. Kocaman, "Providing Cost Save by Using Electronic Meters in Residental Areas", Bitlis Eren Univ J Sci \& Technol, 6 (1), 29-32, 2016.

[30] F. Yiğit ve A. Kabul, "Isparta Yöresinde Bir Evin Elektrik İhtiyacının Rüzgar Enerjisi ile Karşılanmasının Ekonomik Analizi”, Makine Teknolojileri Elektronik Dergisi, 11(2), (1-9), 2014.

[31] S. Altıkat ve A. Çelik, "Iğdır İlinin Hayvansal Atık Kaynaklı Biyogaz Potansiyeli”, Iğdır Üni. Fen Bilimleri Enst. Dergisi, 2(1), 61-66, 2012.

[32] N. Nacar Koçer ve G. Kurt, "Malatya'da Hayvancılık Potansiyeli ve Biyogaz Üretimi”, SAÜ. Fen Bilimleri Dergisi, 17. Cilt, 1. Say1, s. 1-8, 2013.

[33] F. Yürük ve P. Erdoğmuş, "Düzce İlinin Hayvansal Atıklardan Üretilebilecek Biyogaz Potansiyeli ve K-Means Kümeleme ile Optimum Tesis Konumunun Belirlenmesi", İleri Teknoloji Bilimleri Dergisi, Cilt 4, Sayı 1, 47-56, 2015.

[34] A. Onurbas Avcioğlu ve U. Türker, "Status and potential of biogas energy from animal wastes in Turkey", Renewable and Sustainable Energy Reviews, 16, pp. 1557-1561, 2012. 